Supplement of Atmos. Chem. Phys., 19, 15199-15216, 2019

https://doi.org/10.5194/acp-19-15199-2019-supplement

(C) Author(s) 2019. This work is distributed under

the Creative Commons Attribution 4.0 License.

(c) (1)

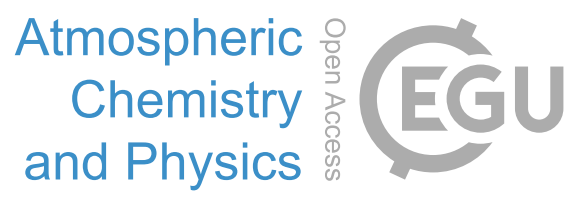

Supplement of

\title{
The role of spring dry zonal advection in summer drought onset over the US Great Plains
}

\author{
Amir Erfanian and Rong Fu \\ Correspondence to: Amir Erfanian (amir.erfanian@ atmos.ucla.edu)
}

The copyright of individual parts of the supplement might differ from the CC BY 4.0 License. 

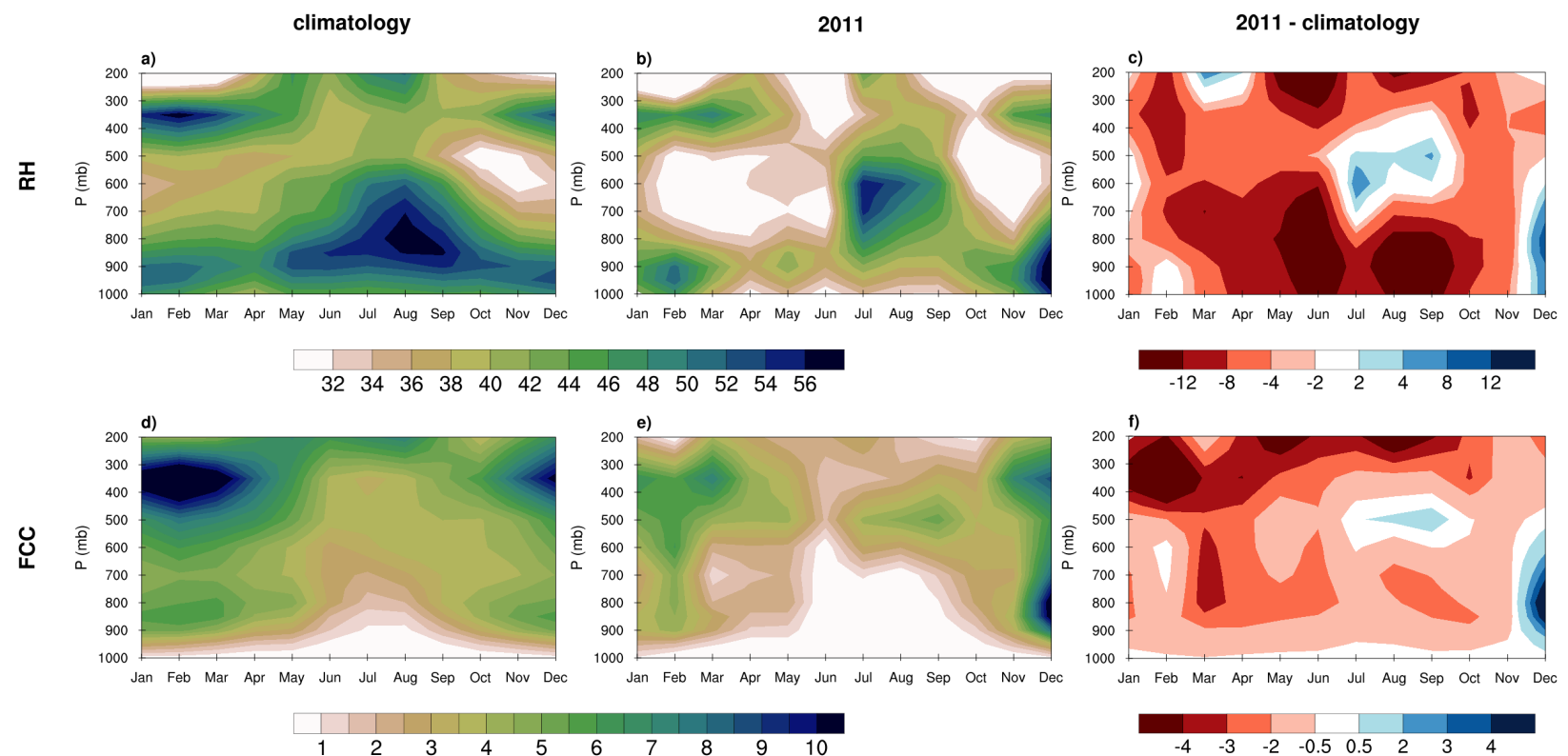

Figure S1. Same as Figure 2 but for (a, b, and c) Relative humidity (\%) and (d, e, and f) fraction of cloud cover (\%).
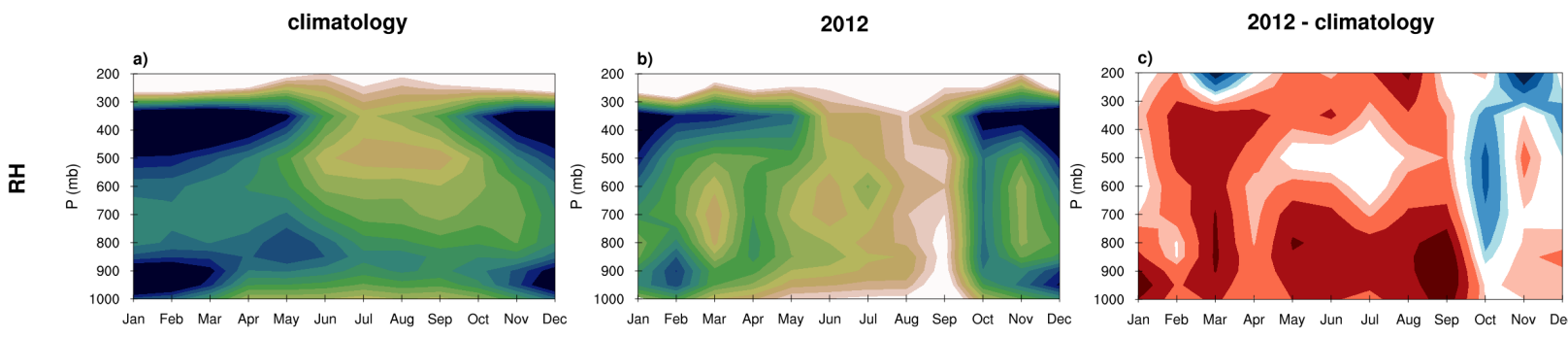

$\begin{array}{lllllllllllll}38 & 40 & 42 & 44 & 46 & 48 & 50 & 52 & 54 & 56 & 58 & 60 & 62\end{array}$
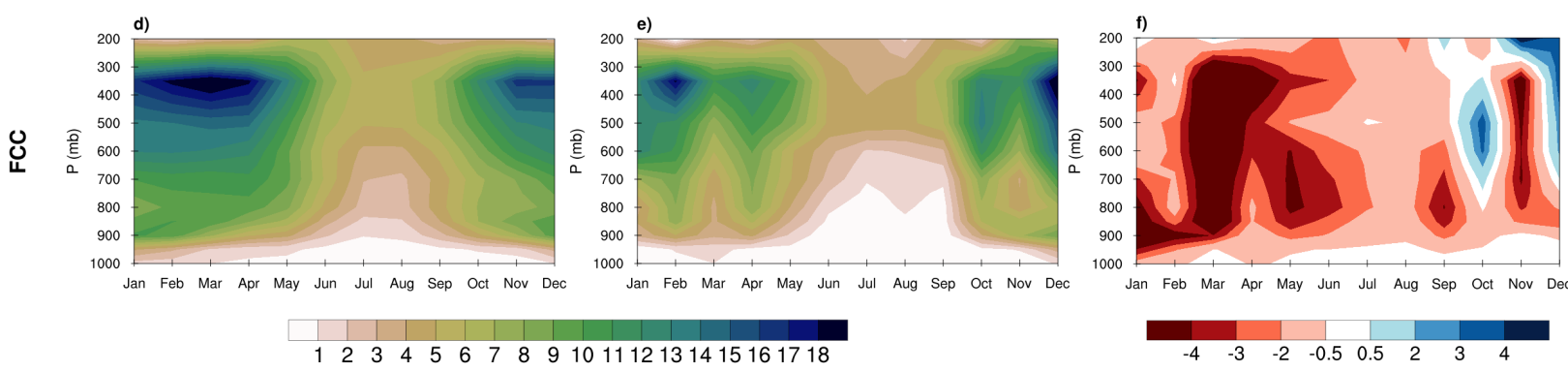

Figure S2. Same as Figure S1 but for the NGP in 2012. 


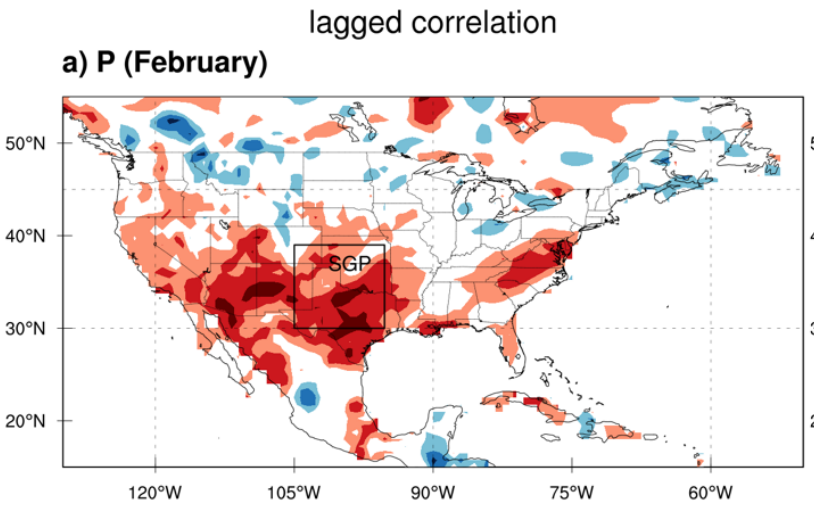
b) $\mathbf{P}$ (June)

lead correlation

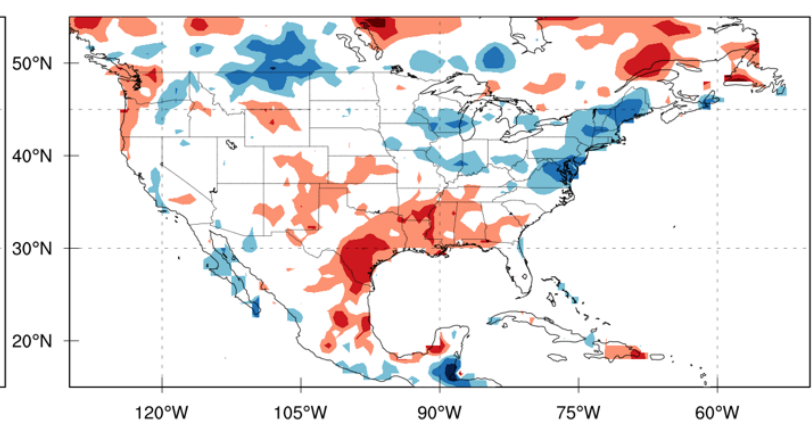

c) $\mathbf{P}$ (March)

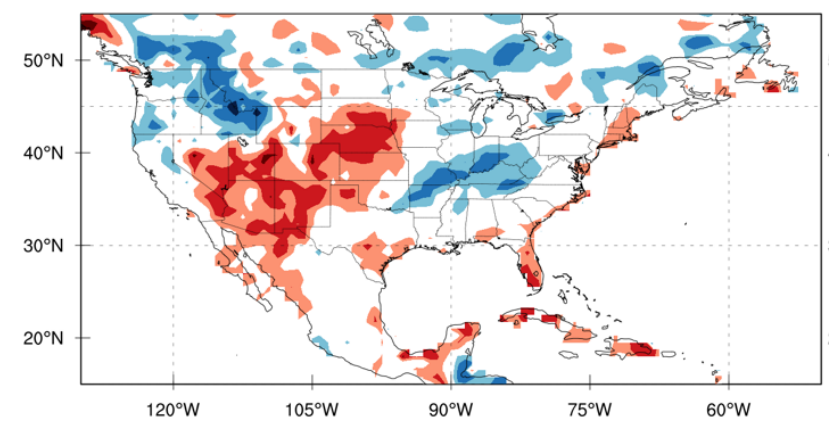

d) P (July)

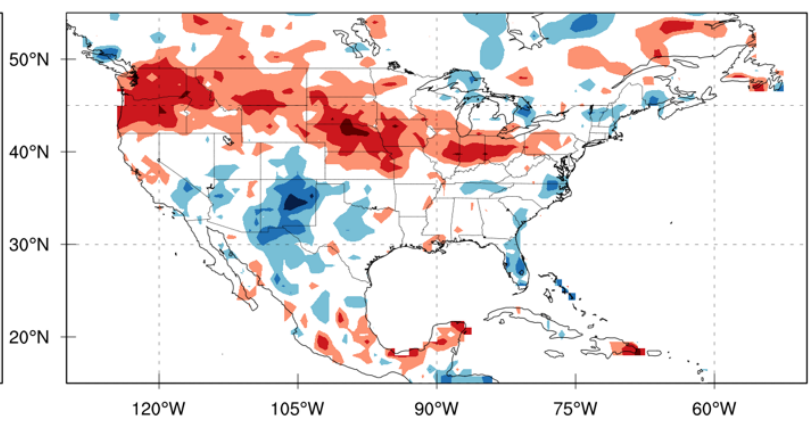

e) $P$ (April)

f) $P$ (August)

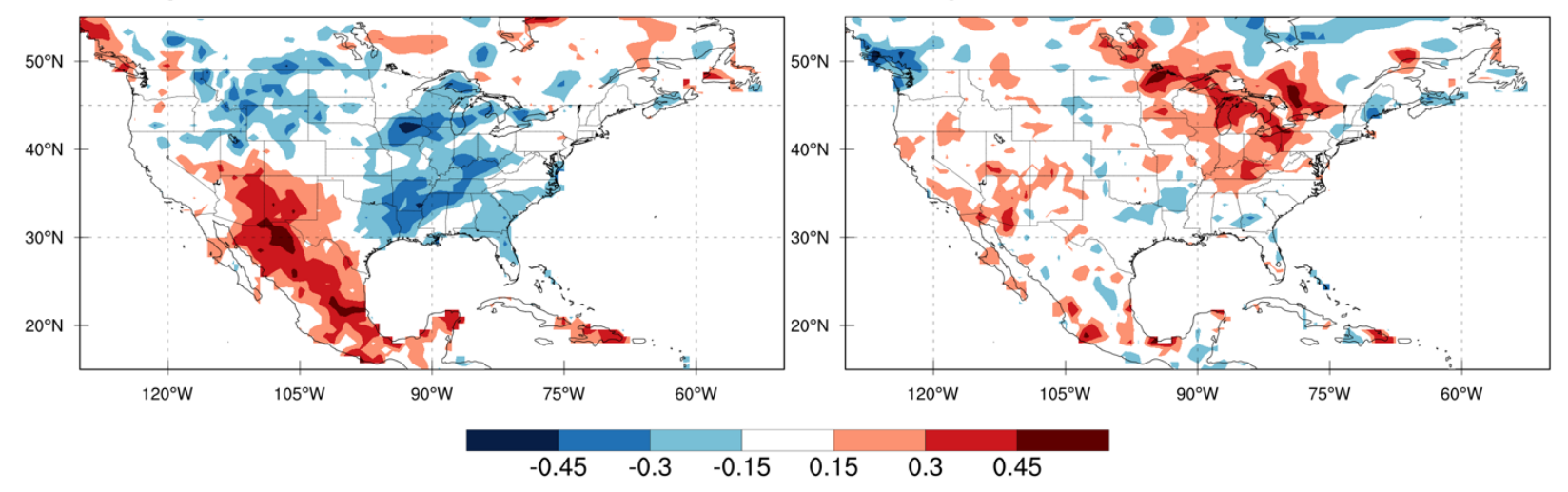

Figure S3. Single point lag/lead correlation maps between the standardized time series of the MAM zonal thermodynamic advection at $700 \mathrm{mb}$ averaged over the SGP (the box in a) with the standardized anomalies of precipitation in a) February, c) March, e) April, b) June, d) July, and f) August using CPC gauged-based precipitation during 1979-2018. The correlation coefficients greater than 0.3 and 0.4 are statistically significant at the $10 \%$ and $2 \%$ levels, respectively (see section 2.6). 
a) P (February)

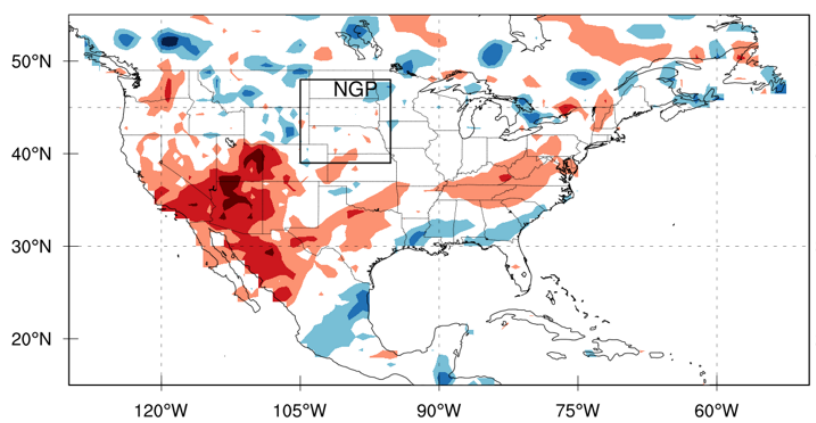

c) $\mathbf{P}$ (March)

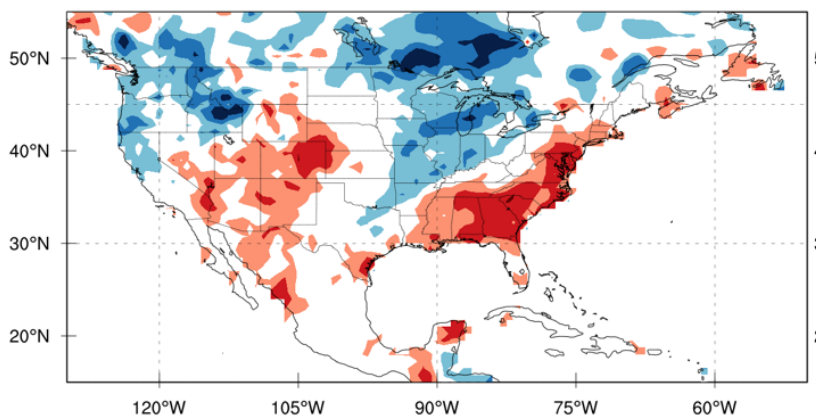

e) $\mathbf{P}$ (April)

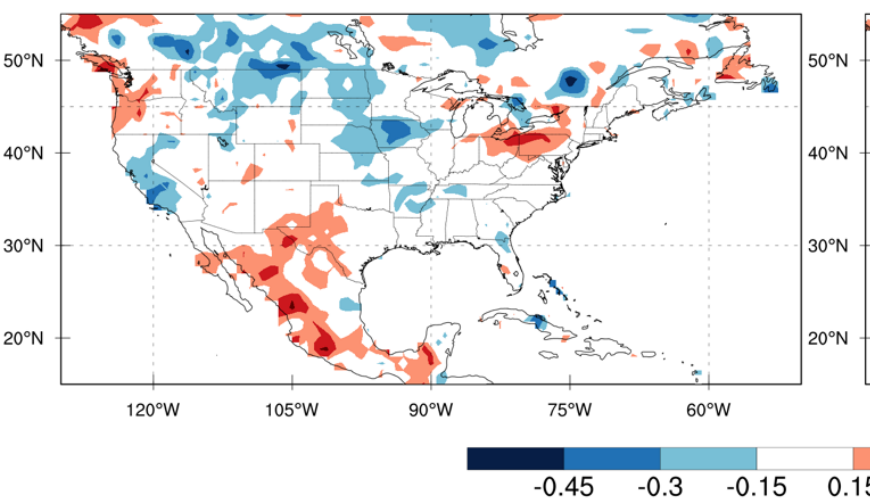

Figure S4. Same as Figure S3 but for the NGP. b) $\mathbf{P}$ (June)

lead correlation

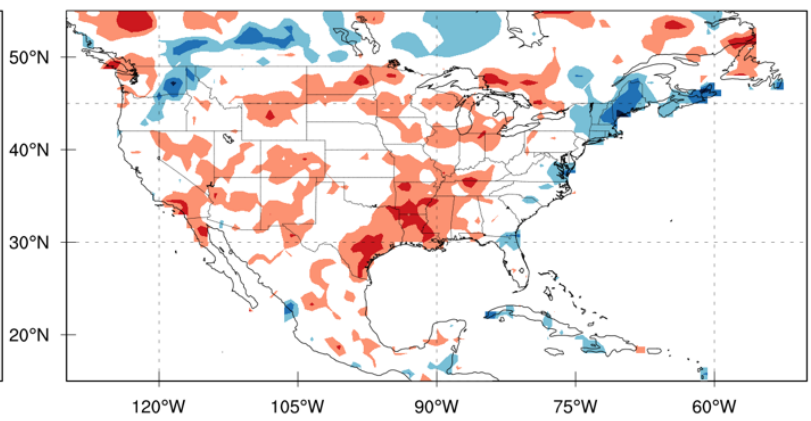

d) P (July)

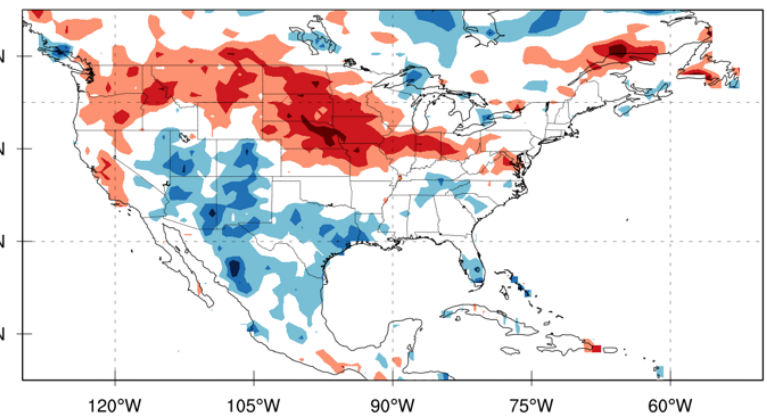

f) $\mathbf{P}$ (August)

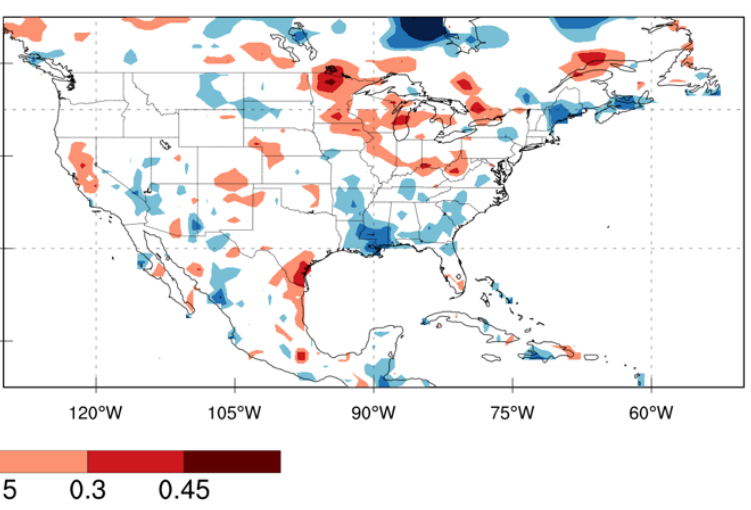


$U$ \& q
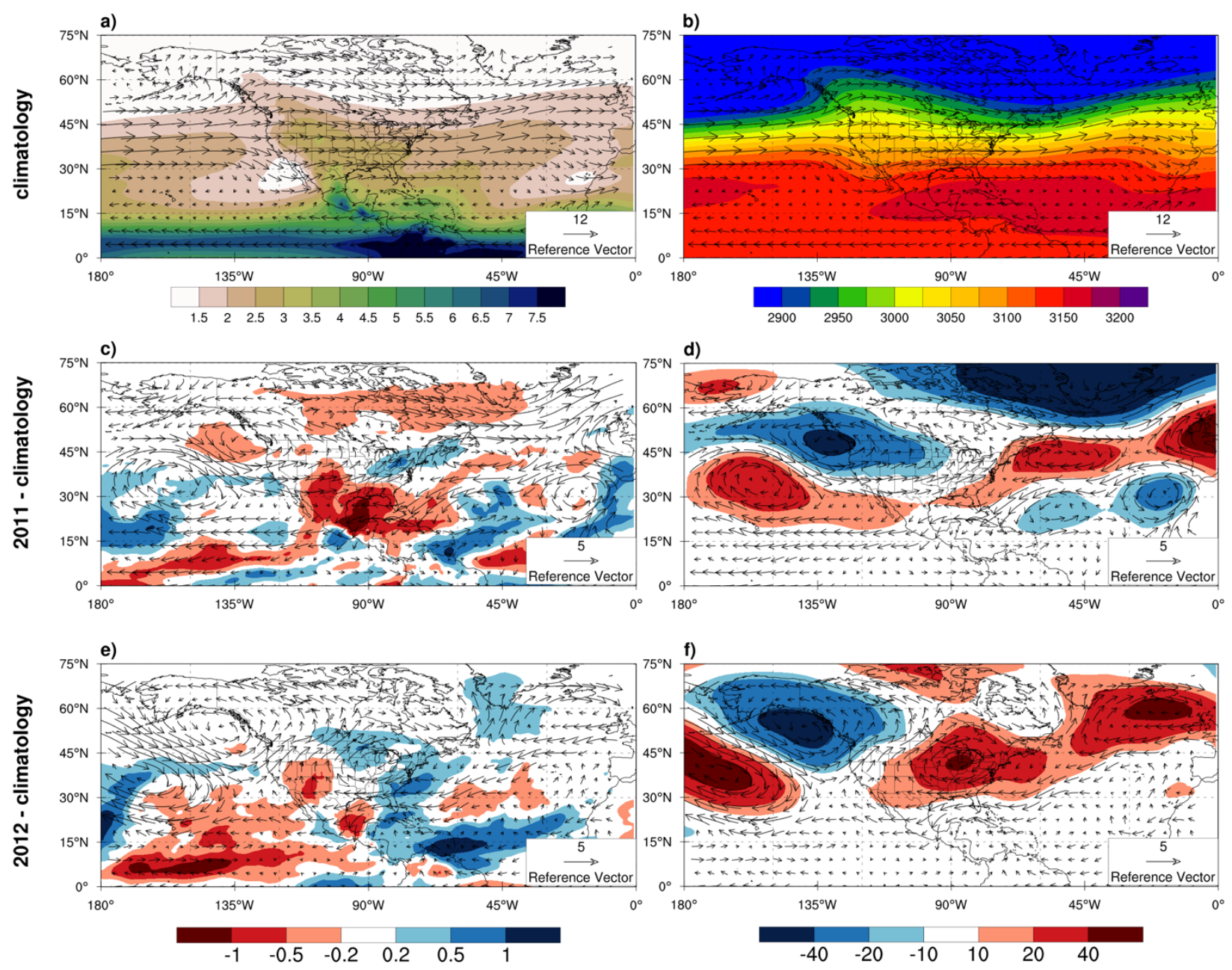

Figure S5. The MAM climatology (a and b;1979-2018) and the 2011 (c and d) and 2012 (e and f) difference fields of $700 \mathrm{mb}$ specific humidity $(\mathrm{g} / \mathrm{kg} ; \mathrm{a}, \mathrm{c}$, and e) and geopotential height ( $\mathrm{m} ; \mathrm{b}, \mathrm{d}$, and $\mathrm{f}$ ) overlaid by the $700 \mathrm{mb}$ horizontal wind $(\mathrm{m} / \mathrm{s})$ vectors in ERA-Interim. 